\title{
MUJERES INDÍGENAS EN CUENCA A FINALES DE LA COLONIA: LA INFORMALIDAD COMO MEDIO DE SUBSISTENCIA
}

\section{INDIGENOUS WOMEN IN CUENCA AT THE END OF THE COLONIAL PERIOD: INFORMALITY AS A WAY OF SUBSISTENCE}

\author{
Elsa Rosario Sinchi Lojano* \\ Miguel Ángel Novillo Verdugo**
}

RESUMEN

\begin{abstract}
El presente trabajo aborda, a través del análisis de fuentes primarias y secundarias, las diversas dinámicas que la población indígena desarrolló en el entorno urbano de Cuenca, Ecuador, a finales del siglo XVIII e inicios del XIX. En este contexto, se reconoce el espacio de participación de las mujeres indígenas, quienes lograron una importante inserción en la estructura económica colonial, mediante la elaboración de manufacturas y la comercialización de productos.
\end{abstract}

PALABRAS CLAVE: ECUADOR * MUJER * COLONIA * INDÍGENAS * TRABAJO

\section{ABSTRACT}

The current work addresses, through the analysis of primary and secondary sources, the diverse dynamics that the indigenous population developed around the urban environment of Cuenca, Ecuador, between the end of the XVIII century and the beginning of the XIX century. In this context, the area of participation of indigenous women will be highlighted, who achieved an activism in the economic organization through the elaboration of crafts and the commercialization of products.

KEYWORDS: ECUADOR * WOMEN * COLONY * INDIGENOUS PEOPLE * LABOUR

Cetro Regional de Estudios Socioculturales (CERES), Ecuador. elsarosariosinchi@gmail.com

** Universidad de Cuenca, Ecuador. miguel.novillo@ucuenca.edu.ec 


\section{INTRODUCCIÓN}

Latinoamérica enfrenta dos grandes problemas en la cimentación de su devenir histórico. Por un lado, está la deconstrucción de la historia eurocéntrica —que distorsiona la visión y el estudio de las culturas que se desarrollaron antes de la conquista europea- $-y$, por otro lado, la deconstrucción de la historia patriarcal - que no visibiliza a las mujeres en los diferentes procesos-. Enmarcado en este último, la historiografía andina ubicaba a la mujer indígena, hasta hace poco, a la sombra de su cónyuge (Guardia, 2016).

Si bien, a nivel de Latinoamérica, algunas obras han puesto énfasis en el papel de las mujeres durante el periodo colonial (Arrom, 1988; Kellogg, 1995; Lavrin, 1985; Rípodas, 1977; Stolcke, 1993), sobre todo con reflexiones dirigidas hacia la situación legal, la normativa de los dotes, los códigos matrimoniales, las estructuras religiosas, civiles y económicas. Sin embargo, es innegable que el tema del aporte de las mujeres en la sociedad aún constituye una urgencia política y académica, pues, se considera que los estudios históricos de las sociedades coloniales - en su gran mayoría- no han dirigido su mirada "hacia esa otra parte" representada y constituida por las mujeres. Esto ha llevado a omitir y soslayar sus actividades, preocupaciones $y$ especificidades. De manera que falta mucho por revertir, transformar $y$ visibilizar a las mujeres en sus espacios, prácticas culturales y participación en la historia local, nacional y mundial.

El argumento expuesto refleja la necesidad de deconstruir categorías absolutas. Para ello se recurre a la perspectiva de género feminista, categoría de análisis que permite identificar la opresión femenina y evidenciar sus espacios de uso y acción, a través del establecimiento de correlaciones entre las posibilidades de vida de mujeres $y$ hombres en el periodo colonial (Lagarde, 1996; Moscoso et al., 2009).

En la Audiencia de Quito y en sus regiones, entre estas, la región Sur cuyo centro era Cuenca - actual ciudad sur andina del Ecuador, ubicada en la provincia del Azuay-, el sistema colonial se caracterizó por el afán de grupos dominantes en obtener mano de obra indígena, a través de modalidades como la encomienda y la mita, coadyuvadas por el sistema del tributo (Stern, 1986; Assadourian, 1982). Estas cargas fiscales pesaban sobre el mundo indígena. Generalmente, las mujeres estaban exentas de las obligaciones fiscales, sin embargo, debían acompañar a su marido en el servicio de la mita en las minas y estaban sujetas a tareas domésticas dentro de las haciendas o en las casas de blancos (Harris et al., 1987). El tiempo que les quedaba libre lo destinaban a la búsqueda de dinero para hacer frente a las obligaciones fiscales de la unidad doméstica, denotando una movilidad económica y social intensa en el periodo colonial.

La población indígena - muy diversa en su interior: caciques, sacristanes, cantores, forasteros y de servicio doméstico-, desde sus distintas particularidades, estaba en relación de servicio con los españoles. En uno de los extremos de la población indígena se encontraban los de origen cacical, cuya estructura fue una de las primeras en reproducirse en el orden colonial, pero con una alteración significativa en sus bases. Por un lado, los y las caciques contaban con el derecho sobre las tierras de comunidad y defendían a las personas indígenas pobres de los abusos de los colonizadores, pero por otro lado, desempeñaron un rol fundamental en el "traspaso de la propiedad indígena a manos españolas y en la extracción de tributos a favor de la corona" (Kennedy y Fauria, 1987, p. 145). Al otro extremo estaban los y las indígenas pobres, quienes fueron sometidos a golpes, azotes, abortos, exceso de trabajo, entre otros abusos $^{1}$, tanto de los y las caciques indígenas como de los españoles. Es este último grupo al cual se hará referencia en el desarrollo del texto. En este mismo sentido, cuando se habla de mujeres indígenas, la referencia es hacia las indígenas del común, que se distancian de las indígenas descendientes de dinastías cacicales ${ }^{2}$ —del antiguo territorio Cañari- quienes

\footnotetext{
1 Revisar ANH/Q, Serie Indígenas, Caja 124, Expediente 10, Quito, 1778, f. 1-2.

2 Poloni (2002) registra en 1650 a María Guayanchug como cacica de Sigsig.
} 
ejercían autoridad y gozaban de mayores oportunidades sociales y económicas.

De allí que, el presente artículo tiene como objetivo principal reconocer los espacios de participación económica y social de las mujeres indígenas en el contexto colonial cuencano de fines del siglo XvIII e inicios del siglo XIX. Los objetivos específicos se centran en describir la incidencia de las reformas borbónicas en la restructuración de la matriz societaria cuencana: etnia, brechas de género y jerarquías sociales, e identificar los espacios y mecanismos de resistencia de las mujeres indígenas ante la presión colonial.

Para alcanzar los objetivos planteados, el desarrollo del presente trabajo fundamenta su reflexión en el estudio de documentos de archi$v^{3}$ que responden a la serie de encomiendas $y$ de tributos, registros que, de manera indirecta y escasa, brindan los indicios de participación económica de la mujer como una respuesta a la presión colonial, a la complementariedad sexual, a su condición y participación dentro de una estructura socioeconómica no preparada para su acción.

Complementario a la revisión de las fuentes directas, se analizan aportes de autores específicos que se focalizan en temas de comercio urbano y en las relaciones jerárquicas de poder económico y social: Minchom (1985), Poloni (1992), Borchart de Moreno (2001).

También se suman a la reflexión los aportes de Elinor Burkett (Lavrin, 1985) y Frank Salomón (1988) quienes plantean una relativa independencia de las mujeres y su papel integrador entre las dos culturas que imprimía una nueva identidad. Igual de importantes son los aportes de Irene Silverblatt (1987) y Luis Miguel Glave (1987), quienes profundizan en la interpretación del género y sus relaciones con las jerarquías de poder y estructuras coloniales, con énfasis en la explotación económica $-y$ sexual- de las mujeres indígenas respecto a los hombres $y$ en la ruptura de las indígenas con

3 Para la denominación de los documentos de archivo se utilizará la nomenclatura ANH/C para el caso de Cuenca; ANH/Q para el caso de Quito. sus sociedades originarias y la formación de nuevas identidades urbanas.

Así, el punto de partida del presente trabajo es el contexto político y socioeconómico de cuenca a fines del siglo xviII e inicios del XIX, cuya característica principal es la implantación de las reformas borbónicas; hecho que determinó la reorganización del espacio social y económico de Cuenca. Seguidamente, el interés se centra en las formas de visibilización y resistencia por parte de las mujeres indígenas ante la presión colonial.

\section{CUENCA A FINALES DEL SIGLO XVIII E INICIOS DEL XIX: INCIDENCIA DE LAS REFORMAS BORBÓNICAS}

A finales del siglo xviII, Cuenca, al igual que Quito y Guayaquil, enfrentó un proceso de reorganización político-administrativo bajo el influjo de las reformas borbónicas ${ }^{4}$ aplicadas por la monarquía española a la Real Audiencia de Quito. La monarquía tras sentir el debilitamiento de los lazos de dependencia de los criollos, buscó por medio de la organización burocrática tener acceso en todas las instancias de la vida económica de las colonias. En este contexto, en el año de 1777, el rey Carlos III decretó la creación de la Gobernación de Cuenca ${ }^{5}$ (ver Imagen 1).

4 Marcan el inicio del período de crisis del Estado colonial en Hispanoamérica, pero que también resultan ser los años de prosperidad económica de Cuenca, mientras que el resto de regiones de la Audiencia de Quito ven descender su crecimiento económico a finales del siglo XviII (Borcharth de Moreno, 2001).

5 Se creó como una unidad subalterna, entendido desde la importancia de las instancias políticas donde el Virreinato de Nueva Granada fue la mayor instancia política, seguida por la Audiencia de Quito, quien ostentó la autoridad política intermedia entre sus espacios regionales y el Virreinato, más no como una limitación de autoridad, ya que en la región, comprendida por las actuales provincias de Cañar, Azuay y Loja, la Gobernación de Cuenca contaba con poder para dirigirla y organizarla (Chacón et al, 1993). 


\section{IMAGEN 1 \\ GOBERNACIÓN DE CUENCA A FINES DEL SIGLO XVIII}

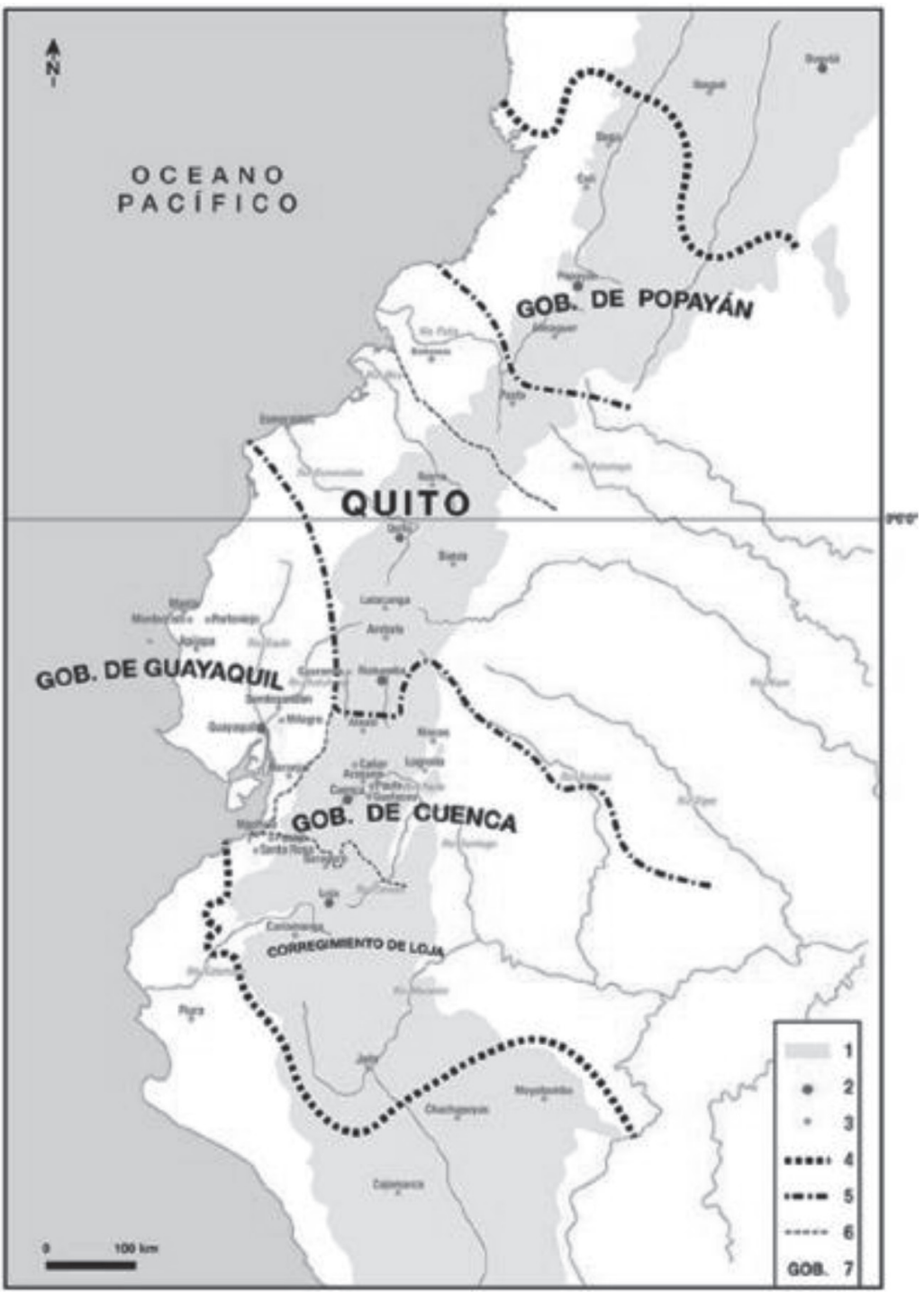

Fuente: Jean Paul Deler, 2007. Adaptado y corregido por Ana Luz Borrero, 2016.

El proyecto borbónico representó para Cuenca un sometimiento administrativo y económico hacia el poder central, aunque no en su totalidad $^{6}$. Pese a la dependencia de origen de

6 Estos acontecimientos históricos se deben a que dentro del Cabildo, el poder era ejercido por los la Gobernación de Cuenca con el Virreinato de Nueva Granada, existía una cierta autonomía

Gobernadores de turno, por tanto, la ejecución de las reformas en el espacio colonial cuencano, dependía de la personalidad e intereses de estos (Ayala y Moreno, 2008). 
política y económica condicionada a cumplir y hacer cumplir el objetivo final de las Reformas Borbónicas (Chacón et ál, 1993); sirva de ejemplo, la exacción económica dirigida a propietarios de tierras, comerciantes y población indígena ${ }^{7}$. De esta manera, con el objetivo de definir a la población tributante $y$ no tributante, la Gobernación de Cuenca llevó a cabo un proceso de identificación de los y las habitantes, basado principalmente en los rasgos étnicos. Razón por la que, a finales del xviII, Cuenca enfrentaba un fuerte proceso migratorio capaz de trasformar el cuadro estático de la sociedad colonial. La nueva dinámica poblacional le permitió a la ciudad experimentar un notable crecimiento demográfico que demandó nuevas exigencias de consumo y comercio.

En este sentido, tanto los cambios administrativos como los tributarios, le permitieron a Cuenca convertirse en el centro del circuito comercial entre el virreinato de Nueva Granada, del que dependía administrativamente; y el de Perú, con el que había fortalecido relaciones comerciales a través de importaciones y exportaciones - sobre todo con el norte peruano(Chacón et ál, 1993).

Para solventar las nuevas necesidades poblacionales, Cuenca necesitó: 1) el incremento de la producción agrícola-ganadera dirigida, mayormente, a satisfacer las necesidades de la población cuencana y 2) El aumento de la producción textil, rebasando los límites locales, dando paso al establecimiento de vínculos mercantiles con Lima por la vía Loja y Piura ${ }^{8}$. Esta dinámica comercial facilitó, inicialmente,

7 Las reformas no afectaron a la población indígena por igual. Por ejemplo, los caciques tenían privilegios, entre estos, se describe la exoneración del pago de tributo, trabajo en las mitas y hasta podían contar con indígenas a su servicio, lo que pone en evidencia una fuerte jerarquización social dentro del mismo grupo. Además, entre los indios tributantes existía una clasificación "de procedencia" para cobro de tributo, lo que marcaba la diferencia en la carga tributaria.

8 Nexo que permitió a la urbe, por un lado, asegurar una producción de tocuyos a gran escala y, por otro lado, obtener materia prima - procedente de la costa del norte del Perú, especialmente de Lambayeque-para la producción textil. inyectar de circulante monetario a la economía cuencana (Espinoza et al., 1982). Por otro lado, la explotación de la cascarilla ${ }^{9}$ le concedió a Cuenca el establecimiento de vínculos mercantiles con el mercado europeo. El afianzamiento de un mercado derivó en la formulación de un circuito comercial que partía desde Guayaquil, pasando por Tumbes y Paita con destino a Lima, luego a Panamá con dirección a Europa (Poloni, 2006).

A diferencia de Cuenca, Quito (capital de la región centro norte de la Audiencia) había basado su economía en la producción minera y textil. Pero, durante la segunda mitad del siglo XVIII, tras la aplicación de las Reformas Borbónicas, la producción textil de los célebres paños azules, decayó (Núñez, 2006). De esta forma, se produjo un estancamiento $y$ una decadencia económica, mientras que Cuenca fortaleció su economía y alcanzó un rápido progreso, a través del refuerzo de su producción artesanal y la comercialización de la cascarilla (Poloni, 2006). Es decir, la condición que favoreció al crecimiento mercantil de Cuenca fue el manejo de economías articuladas, producidas en núcleos familiares, donde dominaba la producción mercantil simple (Espinoza et al., 1982). Pese a la crisis en la Audiencia, la producción a pequeña escala - más de autoconsumo que de comercio - fue un factor decisivo para aislar a la región cuencana de una depresión económica. También le benefició la cercana ubicación de la localidad con respecto al Virreinato del Perú. Puesto que le significó ser el centro de las relaciones comerciales entre Quito, Guayaquil y Piura, a la vez que le permitió tener relaciones directas con el norte del Perú, tanto en abastecimiento de materia prima como en la comercialización de sus productos.

El repentino desarrollo productivo de Cuenca se debió, en gran medida, a la mano de obra indígena; su fuerza de trabajo ayudó al crecimiento de las distintas producciones:

9 También conocida como quinua. Es una planta medicinal utilizada para el tratamiento de las "fiebres intermitentes" o paludismo. Durante el siglo XVII y gran parte del XVIII, el abastecimiento mundial de este producto fue sostenido por la Audiencia de Quito, sobre todo por Loja y Cuenca. 
agrícola, ganadera y manufacturera. Esta última, no fue el principal medio por el cual Cuenca consiguió la monetización, sin embargo, le permitió la acumulación de capital, pues tuvo un alto impacto a nivel de las economías domésticas (Poloni, 2006).

No obstante, esta prosperidad se vio afectada en el momento en el que la exportación de la cascarilla disminuyó notablemente debido al agotamiento de los bosques y la competencia producida por la repentina liberación de otra variedad de cascarilla, desde los bosques de la ciudad de Loja al mercado neogranadino. Asimismo, otro factor que afectó a la prosperidad económica cuencana fue la interrupción de la producción textil que tuvo lugar en las últimas décadas del siglo XVIII, cuyas causas están ligadas al debilitamiento de las relaciones coloniales generadas por los problemas bélicos que enfrentaba la Corona española, así como por los conflictos ideológicos — de la lucha por el poder- existentes dentro de la regiones de la Audiencia.

En términos generales, la etapa de inestabilidad económica que atravesó Cuenca, obligó a la población - sobre todo a la identificada dentro de los sectores subalternos de la sociedad- a buscar nuevas formas de subsistencia que les permitiera satisfacer sus necesidades individuales y familiares. Con ello se desencadenó un crecimiento del comercio al por menor, actividad en la que la población indígena, sobre todo las mujeres, tuvieron una amplia participación.

\section{EL ESPACIO SOCIOECONÓMICO DE CUENCA}

La estructura económica que Cuenca desarrolló dentro del contexto de las Reformas Borbónicas configuró a una sociedad dividida en dos grupos sociales. En primer término, la élite mercantil que ostentó el poder en la sociedad colonial, incluido dentro de este grupo no solo los blancos, sino también a los indígenas caciques y a su familia. En un segundo término, los sectores populares caracterizados por su amplia heterogeneidad y por la enajenación del poder social y político. Estos grupos se encontraban distribuidos tanto en el espacio urbano como en el rural de la localidad cuencana.

De acuerdo al censo poblacional realizado entre 1778 y 1779, bajo el gobierno de Antonio Vallejo y Tacón, en la región de Cuenca -espacio que comprendió las actuales provincias de Azuay y Cañar- la población ascendía a 81246 habitantes: $67 \%$ eran indígenas y el $33 \%$ eran blanco-mestizos (Chacón et al., 1993). De esta manera, a nivel regional, la población indígena fue mayor en comparación a la población blanca y mestiza, mientras que en la ciudad, la repartición étnica evidenciaba lo contrario (tabla 1).

TABLA 1

REPARTICIÓN ÉTNICA DE LA CIUDAD DE CUENCA

1778

\begin{tabular}{l|cccccc|c}
\hline \multirow{2}{*}{ BARRIOS } & \multicolumn{2}{|c}{ BLANCO-MESTIZOS } & \multicolumn{2}{c}{ INDÍGENAS } & \multicolumn{2}{c}{ NEGROS } & \multirow{2}{*}{ (LIBRES Y ESCLAVOS) } \\
\cline { 2 - 6 } & Número & $\%$ & Número & $\%$ & Número & $\%$ & \\
\hline Vecino & 4554 & 63,5 & 2384 & 33,2 & 234 & 33,3 & 7172 \\
Ejido & 926 & 45,6 & 1607 & 52,2 & 39 & 1,9 & 2032 \\
San Sebastián & 3394 & 74,1 & 1020 & 23 & 129 & 2,9 & 4443 \\
San Blas & 223 & 20 & 811 & 72,7 & 82 & 7,3 & 1116 \\
\hline TOTAL & 8997 & 60,9 & 5282 & 35,8 & 484 & 3,3 & 14763 \\
\hline
\end{tabular}

Fuente: Censo de Vallejo (Poloni, 1997). 
Pese a las limitaciones que pueda evidenciar la fuente ${ }^{10}$, es claro que el centro de la ciudad era habitado por una mayoría de blancosmestizos, mientras que los indígenas alcanzaban un tercio de la población. Así, los barrios de la ciudad fueron clasificados en barrios de blancos, de indios y de mestizos, de acuerdo a la condición socio-étnica de sus habitantes.

IMAGEN 2

\section{CONFIGURACIÓN SOCIO-ÉTNICA DE CUENCA SIGLOS XVI-XVIII}

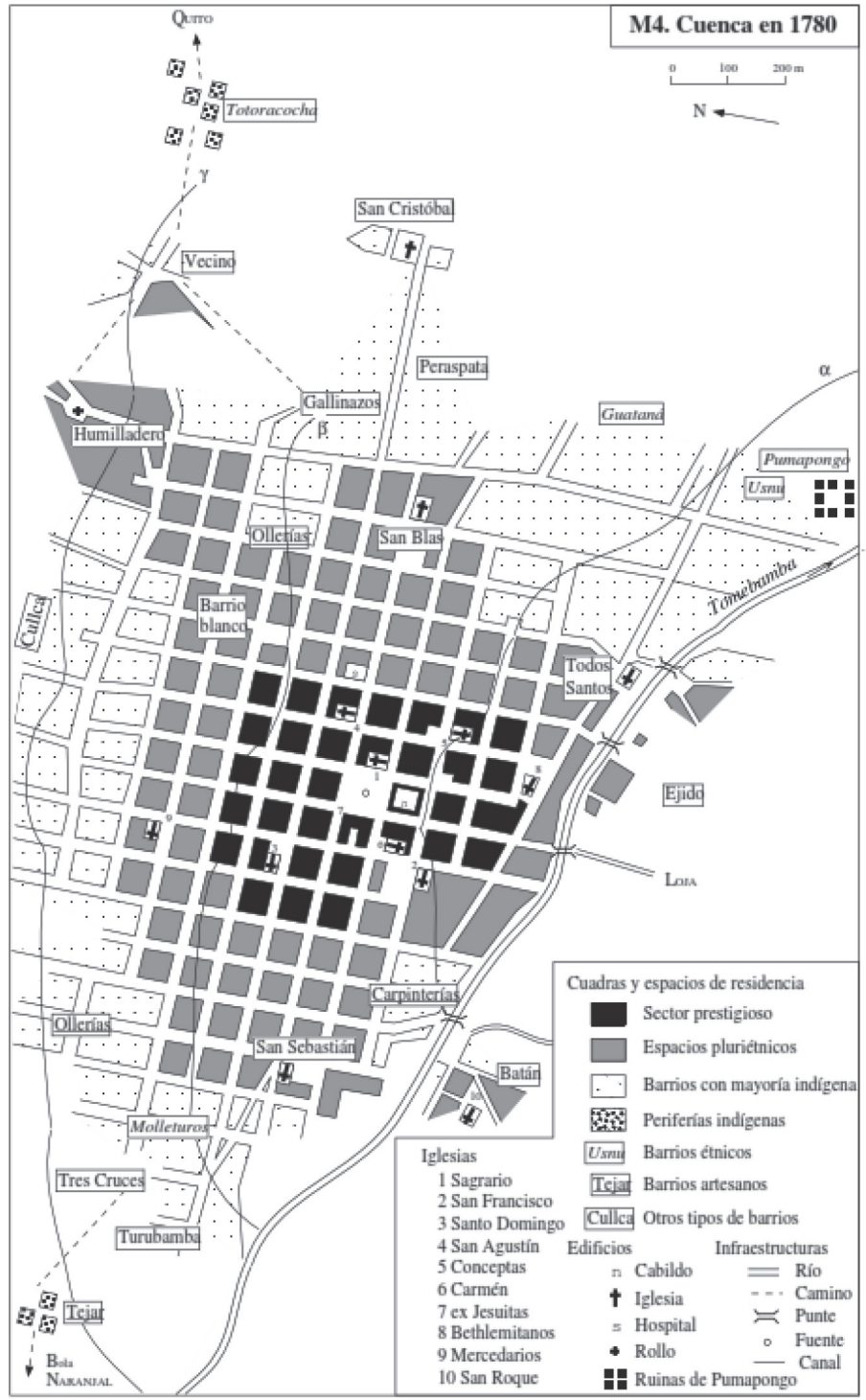

Fuente: $\quad$ Poloni (1997, p 435).

10 Jaques Poloni advierte que el censo de Vallejo identifica que el barrio céntrico, llamado "Vecino" no constituía un "ghetto" blanco; solamente era el sector de mayor prestigio de la ciudad. 
En la imagen 2, en el plano de la ciudad se evidencian zonas de prestigio, espacios pluriétnicas, barrios con mayoría indígena, periferias indígenas, sectores artesanales. Sin embargo, no es posible hablar de espacios meramente homogéneos. Pese a la gran segregación étnica que existió en la época, el área urbana de la ciudad sirvió de plataforma para la interacción entre los sectores de la élite con los sectores populares ${ }^{11}$. La tabla 2 evidencia el mestizaje no solamente a nivel de "barrio", sino también de unidad de residencia en San Sebastían.

TABLA. 2

EL MESTIZAJE EN LAS UNIDADES DE RESIDENCIA SAN SEBASTIÁN, 1778

\begin{tabular}{l|c|c|c|c}
\hline TIPOS DE MESTIZAJE & $\begin{array}{c}\text { NÚMERO DE } \\
\text { UNIDADES } \\
\text { (CASAS Y } \\
\text { TIENDAS) }\end{array}$ & $\%$ & $\begin{array}{c}\text { NÚMERO DE } \\
\text { RESIDENTES }\end{array}$ & $\%$ \\
\hline Españoles-Indígenas & 38 & 7,1 & 323 & 7,3 \\
Mestizos-Indígenas & 95 & 17,8 & 815 & 18,3 \\
Españoles-Mestizos-Indígenas & 82 & 15,3 & 1186 & 26,7 \\
Españoles-Mestizos-Indígenas-Negros & 24 & 4,5 & 429 & 9,7 \\
Mestizos Indígenas-Negros & 9 & 1,7 & 157 & 3,5 \\
Españoles-Indígenas-Negros & 6 & 1,1 & 80 & 1,8 \\
Indígenas- Negros & 1 & 0,2 & 24 & 0,1 \\
Indígenas & 29 & 5,4 & 111 & 2,5 \\
Españoles & 35 & 6,5 & 208 & 4,7 \\
Mestizos & 154 & 28,8 & 835 & 18,8 \\
Españoles-Mestizos & 28 & 5,2 & 240 & 5,4 \\
Otros tipos (Esp.-Negr.,Mest.-Negr.,Esp.-Mest.-Negr.) & 8 & 1,5 & 55 & 1,2 \\
Unidades vacías & 26 & 4,9 & 0 & - \\
\hline TOTAL & 553 & 100 & 4443 & 100 \\
\hline
\end{tabular}

Fuente: Poloni (1997, p 442).

Con el 49\% de las viviendas pluriétnicas, el "barrio" San Sebastián es un ejemplo del dominio del mestizaje en el espacio urbano. Así, el intento de un "desarrollo separado" entre blancos e indígenas de los inicios de la colonia,

11 Hace referencia a los sectores sociales menos favorecidos, dentro de ellos, indígenas y mestizos. se disolvió hacia finales del siglo XviII con la cohabitación cotidiana de diversos grupos en el espacio urbano que rompieron con los límites étnicos preexistentes dentro de la cuidad.

En el contexto general, la población blanca estaba asociada con los cargos públicos y con el manejo de las haciendas, mientras que la población indígena y mestiza estaba relacionada con la producción artesanal, la producción 
independiente $y$ con el comercio al menudeo (Chacón et ál, 1993). En estas dos últimas actividades, figuraba, principalmente, el sector indígena pobre, compuesto por comerciantes a pequeña escala, arrieros, jornaleros, campesinos y campesinas de subsistencia, pequeños tenderos, todos ellos integrados al mercado colonial del trabajo, pero de manera subordinada (Poloni, 2006).

La población indígena masculina que se encontraba fuera del marco de la mita o el concertaje, alquilaban su fuerza de trabajo como personal de haciendas. Con ello mantenían una fuerte relación con la tierra y la actividad agrícola.

Por su parte, la población indígena femenina constituyó mayormente el personal de servicio doméstico, pero también hubieron quienes tuvieron un lugar específico en la estructura económica de la ciudad: las ocupadas en el sector artesanal, las propietarias de tiendas, las productoras de textiles o las pequeñas comerciantes que trabajan en la plaza y calles de la ciudad. En este sentido, la oposición entre los espacios urbanos y los rurales fueron habilitados como espacios económicos para los grupos menos favorecidos y resultaron convenientes para el desarrollo mercantil y para el establecimiento de nuevas relaciones sociales.

La actividad mercantil ejercida por la población indígena consistió, básicamente, en el abastecimiento "legal" e "ilegal" de productos alimenticios a la ciudad. De este modo, tiendas, portales y plazas sirvieron como centro de abastecimiento de artículos de consumo: sal, ají, velas, manteca, verduras, carnes, frutas y otros productos (Chacón et ál, 1993). El caso del contrabando, pese a que siempre representó un problema económico para la Gobernación y para los pulperos, favoreció a la economía de sus actores directos y sus familias.

Por otro lado, el comercio ejercido desde las tiendas y pulperías había experimentado un notable crecimiento durante las dos últimas décadas del siglo xviII. De acuerdo a Chacón et ál (1993), en el año 1808, se registran 50 pulperías, algunas de ellas de pertenencia indígena. Sobre el comercio realizado en las plazas y calles de la ciudad, figuraban las indígenas pobres como protagonistas principales.

En este sentido, la población indígena durante el período colonial tuvo una activa participación en la economía colonial que, consecuentemente, la llevó a representar una base sólida del desarrollo económico de Cuenca y de la población dominante.

\section{MUJERES INDÍGENAS EN EL MERCADO COLONIAL CUENCANO}

El análisis de la matriz societaria cuencana - determinada por etnias y marcada por brechas de género $y$ jerarquías socialesevidencia claras diferencias entre las mujeres indígenas del espacio rural, las mujeres blancas de la élite y las mujeres mestizas e indias del casco urbano; la distancia entre ellas no solo está establecida por las diferencias económicas y culturales (Bourdieu, 2000), sino también por las diferencias étnicas. Aunque en su conjunto tuvieron importante presencia e influencia en la vida pública y privada $^{12}$, las voces de las mujeres, principalmente las indígenas, tienen un eco débil, casi silencioso en los documentos históricos, más sobresalen los casos de violencia a los que estaban expuestas ${ }^{13}$. Sin embargo, las

12 Como lo mencionó Jenny Londoño (1997), las mujeres de la élite desarrollaron actividades económicas en su ámbito de propietarias e, inclusive, hubo quienes ejercieron con excelencia trabajos considerados masculinos. Fueron variados los trabajos asignados a las mujeres de las etnias oprimidas, de los estratos sociales subordinados y a mujeres de todas las edades, pues era común explotar la mano de obra infantil y de las adultas mayores. Duras y largas jornadas de trabajo debían afrontar las mujeres esclavas, indígenas y mestizas, levantándose al alba para cumplir con sus tareas domésticas. Otras, como las mercaderas, debían desplazarse a través de duros y peligrosos caminos, a veces cargando sus criaturas a la espalda, mientras trabajaban bajo un sol inclemente o empapadas por la lluvia.

En un documento de 1682, se registran las arbitrariedades de dos tenientes pedáneos propietarios de la hacienda el Molina, ubicada en Hatún Cañar. En el texto consta la acusación hacia uno de ellos —Don Ignacio de la Peña- por repartir golpes y azotes a los indios, abusar del trabajo de los indios $y$ de haberle provocado el aborto a una india tras haberle golpeado (ANH/Q, 1682). 
mujeres indígenas a través de sus "obligatorias presencias", viven, resisten y complejizan (conflictúan) campos sociales distintos a los tradicionales considerados por la historiografía ${ }^{14}$.

En Cuenca, las mujeres indígenas, al igual que en el caso de Quito, no se limitaron específicamente a cumplir los tradicionales roles impuestos por la sociedad patriarcal, es decir, ser reproductoras y amas de casa. Tuvieron una importante presencia e influencia, tanto en el ámbito público como en el privado (Londoño, 1997).

Muchas mujeres indígenas aparecen vinculadas al servicio doméstico; unas son entenadas, otras son las esposas de los trabajadores $y$ otras son hijas de las esposas de los trabajadores. Como lo anticipa Glave (1987), en la propia ciudad, el servicio doméstico estaba allí para sujetarlas. La domesticidad femenina es posible distinguirla a través de las donaciones de tierras que recibían algunas indígenas de parte de sus amas en retribución de sus servicios personales. No es un caso aislado el de Magdalena Zuchud, india de Azogues, quien en el año de 1670, pidió a María Madalena de Benalcazar, una cuadra y media de tierras por los servicios prestados (ANH/A, Serie Juicios, 1670). De igual manera están los casos expuesto a través de las quejas: María Guarisela ${ }^{15}$ expresaba que desde muy joven ha trabajado en varias casas prestando sus servicios, pero que en varias de las casas donde ha trabajado ha recibido maltratos. De manera que la domesticidad se presenta, por un lado, como una forma de explotación y una modalidad de dependencia, por otro lado, se muestra como un mecanismo para salir de la exclusión al que estaba sometida e, incluso, podía significarles beneficios personales y sociales.

Otras mujeres indígenas aparecen en un lugar más específico de la estructura económica

14 Para el caso Andino, son pocos los trabajos específicos acerca de la historia de las mujeres indígenas en la Colonia. Existen en mayor número los aportes referentes a la múltiple presencia y participacion en la sociedad contemporánea, tanto en el quehacer social como en el político.

15 Queja sobre explotación de sus servicios (ANH/A, 1800). productiva de la ciudad, aquellas ocupadas en el sector artesanal: las tejedoras y las trabajadoras en la elaboración de velas, $y$ otras actividades ${ }^{16}$.

Silvia Palomeque (1979) afirma que la presencia de las mujeres indígenas en la elaboración de tejidos es notoria. Un documento de 1741 hace mención de que son varios los indios y las indias pobres que obtienen de sus ovejas, lana para hilar $y$ vestirse haciendo bayetas, o para la paga de tributos ajenos ${ }^{17}$. En 1765, Joaquín Merizalde (1975), al expresar las dificultades de comercialización que enfrentan los tejidos locales al competir con los tejidos procedentes desde Europa, también deja en claro la relación de los tejidos con las mujeres: “...Las bayetas y lienzos de algodón que deben su ser al trabajo de las mujeres... Hilan todo el año con tesón infatigable, $y$ no logran más que el fruto que la ocupación del tiempo que gastan..." (p. 26).

Al respecto de la elaboración de velas, una demanda ${ }^{18}$ en el año 1677, interpuesta por los caciques de algunos pueblos de Hatun Cañar en contra de Gabriel Maldonado, registra que las indias solteras eran solicitadas para elaborar velas y que no se le pagaba por su trabajo. Otro ejemplo que vincula a las indígenas en esta actividad es el caso de Magdalena Xara, citado por Jaques Poloni (2002), se trata de un juicio entre su albacea testamentaria $y$ sus acreedores, priostes y mayordomos de nada menos que 18 cofradías, estos reclamaban haberle entregado cera a la difunta para hacer velas y cirios, pero la fabricación quedó inconclusa, por lo cual reclamaron la devolución de la materia prima o el pago de los pedidos.

$16 \quad$ Por ejemplo, Jaques Poloni (2006) cita el caso de la india Micaela Rondan que ocupaba, bajo arriendo, uno hornos de leña para hacer teja. Aunque el autor indica que el caso es excepcional, no deja de ser importante la mención, porque a fin de cuentas, evidencia la presencia de las indias en esta actividad económica.

17 Expresado por los caciques en nombre de los indios del pueblo de Gima (ANH/Q, 1741).

18 También consta en el documento que los caciques no les pagaban por su trabajo y exigían que les dieran tributos (ANH/Q, 1667). 
De manera menos común aparecen las mujeres que no tienen un lugar específico en la estructura económica colonial cuencana, pero que están presentes. Se trata de pequeñas comerciantes de bebidas y comidas que trabajan en las calles centrales de la ciudad. La informalidad fue una práctica ejecutada desde las formas más simples a las más complejas. En este escenario fueron inevitables los tratos entre indias y comerciantes al por mayor, las primeras compraban, vendían y daban lugar a pequeñas formas de comercio - que servía de sustento de sus hogares-y los segundos, eran quienes se favorecían de las primeras para establecer las grandes redes de comercio a nivel regional.

En la relación comercial entre las indias con los comerciantes es posible apreciar cómo las mujeres indígenas aparecen subordinadas por los mayoristas. La subordinación se presenta dada la necesidad que tenían ellas de adquirir dinero para resolver necesidades de consumo en el mercado urbano y también para el pago del tributo $\mathrm{u}$ otras pensiones que el marido, hermanos o hijos habían adquirido.

Este hecho les llevaba a solicitar "adelantamientos" de dinero — también de algodón o tejidos- que debían pagar con trabajo, principalmente con tejidos, actividad que parece haber generado una forma más consistente de trabajo por "encargo" en el que los comerciantes adelantan un dinero a las indígenas para que estas tejan tocuyos y bayetas (Moya, 1994). Al final, estos productos eran destinados a la venta o al consumo propio del comerciante.

Además, la venta de alimentos a pequeña escala también estaba condicionada a los grandes comerciantes. Muchos de los alimentos que adquirían las indígenas para venderlos estaban "fiados", lo que le significaba una forma de endeudamiento previo con los mayoristas (Espinoza et al., 1982). Dichas ventas constituían una forma de especulación disimulada, solo posible gracias a la escasez de circulante para las pequeñas vendedoras ${ }^{19}$. En este contexto, aparecen las "gateras", referido a las vendedoras de productos comestibles; las "regatonas", referido

19 Las regatonas eran vendedoras de sal $y$ de alfalfa (ANH/A, 1721). a las vendedoras de sal; las "yerbateras", referido a las vendedoras de alfalfa, entre otras.

Estas actividades no reflejan el cuadro completo del papel económico de la mujer indígena, apenas enfoca algunos elementos de su participación en los circuitos comerciales de una economía local. Sin embargo, se reconocen a las labores vinculadas al servicio doméstico, a la actividad textil, a la venta informal $y$ a pequeña escala de productos alimenticios, como formas de conseguir ingresos complementarios para la subsistencia y mantención familiar, a la vez de ser un mecanismo de visibilización social.

Las necesidades económicas que enfrentaban las familias indígenas conducían a la mujer - como madre, esposa o hermana- a buscar un medio de subsistencia con el desarrollo del comercio a pequeña escala. Si bien, en el caso de las mujeres indígenas no existía impedimento legal que les prohibiera dedicarse por su propia cuenta al comercio ${ }^{20}$, no se puede negar que ante las grandes brechas étnicas, de género y de clase, fue un verdadero reto para las indígenas insertarse en las redes de comercialización. El hecho de que las mujeres accedieran a una economía independiente, producto de una desempeñada labor económica y social, hace mucho más relevante su rol histórico, en función del protagonismo que tradicionalmente se les ha adjudicado.

\section{PLAZA Y CALLES URBANAS COMO ESPACIOS DE VISIBILIZACIÓN}

La gran movilización de las mujeres indígenas en el campo de la economía se expresa con su presencia constante en los mercados ambulantes como vendedoras. También alternando su función de madres en el hogar con las actividades artesanales de hilado y tejido, asimismo, pagando con su mano de obra el

20 Como sí sucedía con las mujeres mestizas del Quito colonial, la mujer mestiza era considerada débil, por tanto, se mantenía bajo un rol de menor de edad (Borcharth de Moreno, 2001). En este sentido, la mujer era incapaz de involucrarse en negocios de cualquier índole, a no ser con el expreso consentimiento del padre o del marido. 
rédito y ayudando en la distribución de alimentos al por menor.

El trabajo domiciliar que ocupaba a las mujeres indígenas en la crianza del ganado lanar $y$ en el tejido de bayetas $y$ tocuyos, las llevaba a vincularse, a través de los grandes comerciantes, al mercado regional, intrarregional y local. En este sentido, el trabajo indígena contribuyó silenciosamente a engrosar los bienes de las mujeres y hombres de las élites, de los comerciantes y de los terratenientes de la ciudad.

Durante las últimas décadas del siglo XVIII e inicios del XIX, en el espacio urbano de Cuenca, carente de un lugar exclusivo para el mercado, se incrementaba la actividad mercantil al por menor. Así, surgían cada vez más tiendas, pulperías y vendedoras libres. Estas últimas se apropiaron de la plaza y las calles principales de la ciudad. Desde allí — un estado de informalidad- las indígenas realizaron actividades comerciales como la venta de chicha, de frutas, de sal, entre otros productos. Así, de acuerdo a los productos que vendrían, se conocían a las chicheras, fruteras, yerbateras, etc., aunque la designación general, sin importar sus especializaciones de venta, fue el de "gateras" — nominación con la que también se identificó a las vendedoras del mercado informal en Quito en el siglo XVII(Minchom, 1996).

Según Poloni (2006), la presencia de las gateras en el espacio público urbano, favorecía a otros sectores pobres como jornaleros o mitayos, cuyos ingresos eran bajos y apenas les alcanzaba para vivir, no así para los dueños y las dueñas de pulperías quienes asociaban a las gateras con el desorden y la competencia comercial desleal, debido a que hacían de las calles y plazas su mercados, sin pagar el alquiler de tiendas para la venta de sus productos.

Más allá, la pobreza en la que se mantenían los sectores populares - vendedoras, pulperos, artesanos, arrieros, hiladoras y tejedores-, los postergaba del respeto social que se atribuía a los sectores dominantes. Una postergación social que no es más que el reflejo de la subordinación social, económica y política que se establecían con base en prejuicios estamentales regulados por la condición socioétnicas de los individuos (León, 1997).

La presencia activa de las mujeres indígenas en la plaza y calles de la ciudad, si bien estuvo condicionada a las necesidades de subsistencia familiar, ya sea por el pago tributario de su marido o por el abandono de este, o por viudez o esposos afectados por el alcoholismo (Poloni, 2006), no se desarrolló como una forma de subordinación al hombre, sino más bien como un mecanismo de cooperación con el mismo, permitiéndole subsistir e, incluso, ganar autonomía económica.

La informalidad de este comercio y la forma particular ${ }^{21}$ de vender los productos adquiridos de los intercambios con los grandes comerciantes o comprados en los caminos reales, entradas y salidas de la ciudad, daban una imagen "holgazana" pero audaz de las mujeres indígenas, en lo que al uso y apropiación del espacio urbano se refiere (Minchom, 1996). Su presencia diaria en la urbe favoreció al contacto directo con grupos sociales opuestos, hecho que contribuyó al quebranto de las barreras étnicas, de género y de clase.

\section{LOS CONFLICTOS DE LA INFORMALIDAD}

La presencia de las mujeres indígenas en los espacios urbanos estuvo marcada por la informalidad - como se ha venido insistiendo a lo largo del estudio-. Al no contar con espacios físicos adecuados para el desempeño de sus actividades mercantiles, ellas optaban por el uso de la plaza y las calles. Armaban pequeños estantes sobre las calles para exhibir sus productos $y$ con ello evitar el alquiler de una tienda, lo que le representaba, de cierta forma, una ventaja en relación a los vendedores de las pulperías que sí lo hacían. Esta característica comercial generaba continuos roces entre las gateras $y$ los pulperos.

La reducción de costos por cuestiones de arriendo permitía a las gateras, a diferencia de los pulperos, ofertar sus productos a menor

$21 \quad$ Exhibían los productos en estantes improvisados $y$ desprovistos de todo arreglo, se sentaban en las aceras de las calles y desde allí expendían sus productos (Poloni, 2006). 
precio. Sin embargo, esta acción perjudicaba a los pulperos quienes cuestionaban la competencia de venta como desleal, además las acusaban de engañar a los compradores en los precios, en la calidad de los productos y la falta de honestidad al momento de la venta. Al respecto, Jaques Poloni (2006), en 1721, registra una demanda por parte de los pulperos en contra de las gateras, la acusación es presentada ante la Caja Real de Loja. Los pulperos acusan a las gateras de actos ilícitos en contra de los compradores, entre los que constan: el comercio informal, la venta de todo tipo de productos (inclusive aquellos que no estaban permitidos), la venta de suministros adulterados, el engaño a los clientes en el peso y medida de los alimentos, $y$ la venta al "fiado". En respuesta a las acusaciones, las gateras, en uso de su derecho de defensa, acudieron al protector de indios. Las justificaciones que entregaban las indígenas obedecían a la necesidad que contar con ingresos complementarios para el sustento de sus hogares. También justificaban que la práctica del trueque y la venta a crédito también eran modalidades practicadas por los pulperos. Además, resaltaban la importancia de mantener esa forma de comercio ante la población más pobre.

Los conflictos entre estos dos sectores permiten comprender la importancia del papel jugado por las mujeres indígenas en la economía cuencana durante todo el siglo xviII $y$ de inicios del XIX, tiempo en el que situación económica de los sectores subalternos se evidencia compleja y en una constante lucha por la subsistencia.

\section{CONCLUSIONES}

Las fuentes sobre las cuales se generaron cuestionamientos y reflexiones, si bien tienen ciertas limitaciones categóricas y numéricas, como es el caso de la clasificación de los sectores populares - quizá por su heterogénea composición, o la ausencia de cifras con respecto a las mujeres indígenas dedicadas a actividades mercantiles-, permiten reconocer a las indígenas como sujetas de autoridad en sus diferentes roles. Asimismo, consienten la identificación de una historicidad de los roles y la naturaleza de la relación entre los dos sexos, sin dejar de lado la interacción y su individualidad en la construcción de sus propias identidades.

Este esbozo del papel de las mujeres indígenas en la economía urbana de Cuenca deja claro que estuvieron activas en los circuitos comerciales de la ciudad, presentes en algunas ramas de artesanía y fueron partícipes de los sistemas de crédito ante la ausencia de numerario, acciones que ponen en evidencia, la subversión de un modelo tradicional unívoco de dominación sobre la sociedad indígena.

La presencia y el accionar cotidiano de las mujeres indígenas en la urbe, en sus calles, en sus plazas, en las casas de los blancos, en los talleres artesanales, sirvió de plataforma habilitante y de visibilización, asimismo permitió que este sector marginado de la sociedad indígena, a través de la informalidad, flanqueara con mayor facilidad las barreras étnicas, de género y de clase de la sociedad colonial cuencana.

\section{REFERENCIAS}

ANH/A. (1670). Serie Juicios. C. 78-625. Azuay. fol. 6 .

ANH/A. (1721). Serie Tributos. C. 94-210. Azuay. f1v.

ANH/A. (1800). Serie Juicios. C. 115-671. Azuay. 4-xii.

ANH/Q. (1667). Serie Tributos. C. 12. Expediente 5. Quito. ff1, 1v, 2.

ANH/Q. (1682). Serie Indígenas. C.14. Expediente 14. Azogues. f4.

ANH/Q. (1741). Serie Diezmos. C. 4. Expediente 15. Quito. f4.

ANH/Q. (1778).Serie Indígenas. C. 124. Expediente 10. Quito. f. 1-2.

Arrom, S. (1988). Las mujeres en la ciudad de México. 1790-1856. Siglo xxI.

Assadourian, C. (1982). El sistema de la economía colonial. Mercado interno, regiones y espacio económico. Instituto de Estudios Peruanos. IEP Ediciones.

Ayala, E. y Moreno, S. (2008). Manual de historia del Ecuador: Épocas aborigen y colonial, independencia. Corporación Editora Nacional.

Borcharth de Moreno, C. (2001). La imbecilidad y el coraje: La participación femenina en 
la economía colonial (Quito, 1780-1830). Antología de Género. FLACso.

Bourdieu, P. (2000). La dominación masculina. Anagrama.

Borrero, A. (2016). Cuenca en la Independencia: de la fidelidad a la insurgencia, 1809-1814. Programa de Doctorado de en Historia. Universidad Andina Simón Bolívar, Sede Ecuador.

Burkett, E. (1985). Las mujeres indígenas y la sociedad Blanca: El caso del Perú del siglo Xvi. En A. Lavrin (comp.), Las mujeres latinoamericanas. Perspectivas históricas (pp. 121-152). FCE.

Chacón, J., Soto, P. y Mora, D. (1993). Historia de la gobernación de Cuenca 1777-1820. IDIS. Universidad de Cuenca, Instituto de Investigaciones Sociales.

Espinoza, L., Achig, L. y Martínez, R. (1982). La Gobernación Colonial de Cuenca. IDIS. Universidad de Cuenca.

Glave, L. M. (1987). Mujer indígena, trabajo doméstico y cambio social en el virreinato peruano del siglo viI: la ciudad de La Paz y el Sur Andino en 1684. Bulletin de l'I.F.E.A., XVI (3-4).

Guardia, S. (2016). Desafíos a la historia de América Latina: una visión de género. Civitas. Revista de Ciências Sociais, 15 (3), e84-e98. https://doi. org/10.15448/1984-7289.2015.3.19530

Harris, O., Larson, B. y Tandéter, E. (1987). La participación indígena en los mercados surandinos. Estrategias y reproducción social. Geres.

Kennedy, A. y Fauria, M. (1987). Obrajes en la audiencia de Quito un caso estudio: Tilipulo. Boletín americanista, 37.

Kellogg, S. (1995). Law and the transformation of Aztec culture, 1500-1700. University of Oklahoma Press.

Lagarde, M. (1996). "El género", fragmento literal: «La perspectiva de género». Género y feminismo. Desarrollo humano y democracia. Ed. Horas y Horas.

Lavrin, A. (1985). Las mujeres latinoamericanas. Perspectivas históricas. Fondo de Cultura Económica.
León, C. (1997). La primera alianza. El matrimonio criollo: honor y violencia conyugal Cuenca (1750-1800). Nueva Editorial.

Londoño, J. (1997). Entre la sumisión y la resistencia: las mujeres en la Real Audiencia de Quito. Abya-Yala.

Merizalde, J. (1975). Relación histórica, política y moral de la ciudad de Cuenca. Casa de Cultura Ecuatoriana.

Minchom, M. (1996). La Economía Subterránea $y$ el mercado urbano: pulperos, indias gateras y recatonas del Quito colonial. Siglo (xvI-XVII). Memorias del Primer Simposio Europeo sobre Antropología del Ecuador. S. Moreno Yánez (Coord). Ed. Abya-Yala.

Moscoso, M., Quinatoa, E., León, E., Moscoso, L. y Carrasco, J. (2009). Historia de mujeres e historia de género en el Ecuador. IPANC-CAB.

Moya, A. (1994). La Cascarilla: Auge y Crisis de la cascarilla en la Audiencia de Quito, siglo XVIII. FLACSO.

Núñez, J. (2006). Regiones y Sociedades Regionales. Colección Cultural «Bolívar, ayer, hoy y siempre». Casa de la Cultura Ecuatoriana.

Palomeque, S. (1979). Historia económica de Cuenca y sus relaciones regionales (desde fines del siglo XVII a principios del XIX). Revista del Archivo Nacional de Historia, Sección Azuay, 1.

Poloni, J. (1992). Mujeres indígenas y economía urbana: el caso de Cuenca durante la colonia. Mujeres de los Andes: Condiciones de vida y salud. Institut Français d'Études Andines.

Poloni, J. (1997). Formación, desarrollo y configuración socio-étnica de una ciudad colonial: Cuenca, siglos XVIXVIII. Tomo LIV, 2. Consejo Superior de Investigaciones Científicas.

Poloni, J. (2006). El mosaico Indígena: movilidad, estratificación social en el corregimiento del Cuenca (Ecuador) del siglo XVI al silgo XVII. Abya-Ayala.

Rípodas, D. (1977). El matrimonio en Indias. Realidad social y regulación jurídica. 
Fundación para la Educación, la Ciencia $y$ la Cultura.

Salomón, F. (1988). Indian women ot early colonial Quito as seen through their testaments. The Americas (AAFH/TAM), 44 (3).

Silverblatt, I. (1987). Luna, Sol y Brujas.

Género y clases en los Andes prehispánicos y coloniales. CBC.
Stern, S. (1986). Los Pueblos indígenas del Perú y el Desafío de la Conquista Española. Alianza Americana.

Stolcke, V. (1993). Mujeres invadidas. La sangre de la conquista de América. Ed. Horas y Horas.

Fecha de ingreso: 23/08/2019

Fecha de aprobación: 14/12/2020 
